\title{
T-Peak to T-End Improvements After Beta-Blocker Administration in Peripartum Cardiomyopathy Patients
}

\author{
Chaerul Achmad a, b, c, Mohammad Iqbal ${ }^{\text {a }}$, Giky Karwiky ${ }^{\mathrm{a}}$, \\ Hawani Sasmaya Prameswaria, Mega Febrianora ${ }^{a}$
}

\begin{abstract}
Background: Many studies have shown that T-peak to T-end (TPTE) interval was associated with sudden cardiac events. Peripartum cardiomyopathy (PPCM) causes reversible left ventricle systolic dysfunction which may deteriorate into sudden cardiac death. This study aimed to evaluate beta-blocker as an antiarrhythmic agent to improve TPTE interval as a prognostic value of sudden cardiac death.

Methods: A cohort experimental prospective study was performed. The PPCM was diagnosed from the emergency ward. A total of 54 cases were identified from 2014 to 2016 . Thirty-four patients were followed up for further analysis. Electrocardiograms were conducted in all the patients, and TPTE interval was measured. After a followup of 6 months of beta-blocker treatment, the echocardiography and TPTE interval were measured again to obtain the repolarization heterogeneity.
\end{abstract}

Results: The mean age of subjects was $32 \pm 6.4$ years. The mean left ventricular ejection fraction (LVEF) was $32.24 \pm 6.3 \%$. The mean TPTE interval was $123.7 \pm 28.2 \mathrm{~ms}$. After 6 months of beta-blocker administration, the mean LVEF was $58.26 \pm 4.4 \%$ and the mean TPTE was $98.7 \pm 39.5 \mathrm{~ms}$. The paired $t$-test showed a significant difference between TPTE interval pre- and post-administration of beta-blocker ( $\mathrm{P}$ value $<0.001)$.

Conclusions: There is an improvement of TPTE in PPCM patients after 6 months of beta-blocker administration. Administration of betablocker in PPCM patients is expected to prevent sudden cardiac death in PPCM populations.

Keywords: T-peak to T-end interval; Peripartum cardiomyopathy; Beta-blocker; Left ventricular ejection fraction; Repolarization heterogeneity

Manuscript submitted March 25, 2020, accepted April 13, 2020

${ }^{a}$ Cardiology and Vascular Medicine Department, Hasan Sadikin General Hospital, Universitas Padjadjaran, Bandung, Indonesia

${ }^{\mathrm{b}}$ Hasna Medika Cardiac Hospital, Cirebon, Indonesia

${ }^{\mathrm{c} C o r r e s p o n d i n g ~ A u t h o r: ~ C h a e r u l ~ A c h m a d, ~ D e p a r t m e n t ~ o f ~ C a r d i o l o g y ~ a n d ~ V a s-~}$ cular Medicine, Faculty of Medicine, Universitas Padjadjaran, Jl. Pasteur No. 38, Pasteur, Sukajadi, Bandung 40161, Indonesia.

Email: chaerula2015@yahoo.com

doi: https://doi.org/10.14740/cr1053

\section{Introduction}

Peripartum cardiomyopathy (PPCM) is defined as pregnancyrelated myocardial dysfunction, which appears during the last month of pregnancy until 6 months after delivery in women without any cardiovascular disease [1]. PPCM could cause serious complications, which may lead to death or severe and prolonged morbidity. There is a higher rate of adverse events, which occur in non-Caucasian patients, mainly related with low left ventricular ejection fraction (LVEF) $(<25 \%)$ at the time of diagnosis [2-4]. The pathophysiology of PPCM confirms that inflammation, oxidative stress, and prolactin could be interrelated in a vicious circle, which is liable for initiating PPCM [5]. Ventricular tachyarrhythmias were presumed as causes of sudden cardiac death (SCD) in at least one-fourth of deaths in PPCM [6]. However, there are limited data on arrhythmic events and the risk for SCD in PPCM. T-peak to T-end (TPTE) is defined as the interval between the peak and the end of $T$ wave on electrocardiogram (ECG). It is recognized that TPTE interval could be used as an index of transmural dispersion of ventricular repolarization [7]. Many studies have shown that TPTE interval was associated with ventricular arrhythmia and SCD. Beta-blocker is one of the cornerstone treatments for PPCM. Beta- blocker has the effect of normalization of ventricular repolarization, particularly in the case of prolonged QT [8-13]. The purpose of this study was to investigate the effects of beta-blocker treatment on the ventricular repolarization by measuring TPTE interval on the 12-lead resting ECG. We analyzed the changes of TPTE interval before and after the initiation of beta-blocker treatment for a period of time. To the best of our knowledge, the effect of beta-blockers on TPTE interval on PPCM population has not been reported before.

\section{Materials and Methods}

This is a prospective cohort study, and patients gave the informed consent. All patients with newly diagnosed PPCM between 2014 and 2016 were included in the study. PPCM was diagnosed based on the PPCM diagnostic criteria in European Society of Cardiology (ESC) guideline, including patients presented with: 1) heart failure (HF) secondary to LV systolic dysfunction, which develops during the end of pregnancy or 6 months following delivery; 2) no identifiable explanation for HF; 3) EF below $45 \%$ based on echocardiography examination [1] 


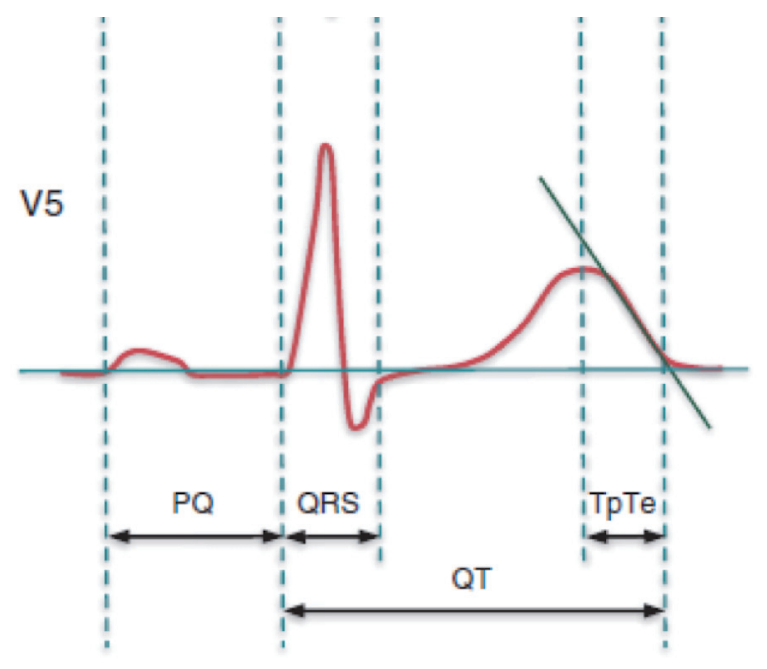

Figure 1. Method of T-peak to T-end (TPTE) measurement in lead V5.

All recruited patients were categorized as New York Heart Association (NYHA) Functional Class (FC) III or IV. The treatment regimen of PPCM consists of titrated beta-blockers (bisoprolol $2.5-5 \mathrm{mg}$, once daily), angiotensin-converting enzyme (ACE) inhibitors, mineralocorticoid receptor antagonists, and bromocriptine as indicated. Data were collected before beta-blocker treatment was initiated; during hospitalization or outpatient clinic follow-up and after 6 months of the treatment of beta-blocker.

Electrocardiographic examinations were conducted on all patients. TPTE was calculated from two continuous beats in selected 12-lead resting ECG lead (V2 - V5). The Lepeschkin's method was used to identify the endpoint of the QT segment by drawing a tangential line from the peak of the $T$ wave to obtain the endpoint of the QT segment from the intersection with the isoelectric line (Figs. 1,2).

\section{Statistical analysis}

Continuous variables are presented as mean \pm standard deviation (SD). The significance of TPTE changes before and after treatment of the PPCM patients were analysed by Student's $t$-test. A P value $<0.05$ was considered statistically significant. Statistical analysis was performed using IBM SPSS Statistics version 20 (IBM, Armonk, NY, USA).

The study protocol was reviewed and approved by Research Ethics Committee, Faculty of Medicine, Padjadjaran University, Bandung.

\section{Results}

During a 3-year enrolment period (2014 to 2016), we diagnosed 54 women with PPCM. Thirty-four patients were followed up (mean age: $32 \pm 6.4$ years). Baseline characteristics of subjects at the time of hospital admission are showed in Table 1 . The mean of body mass index was $24.87 \pm 3.2 \mathrm{~kg} / \mathrm{m}^{2}$. The mean of systolic blood pressure was $118 \pm 11.4 \mathrm{~mm} \mathrm{Hg}$,

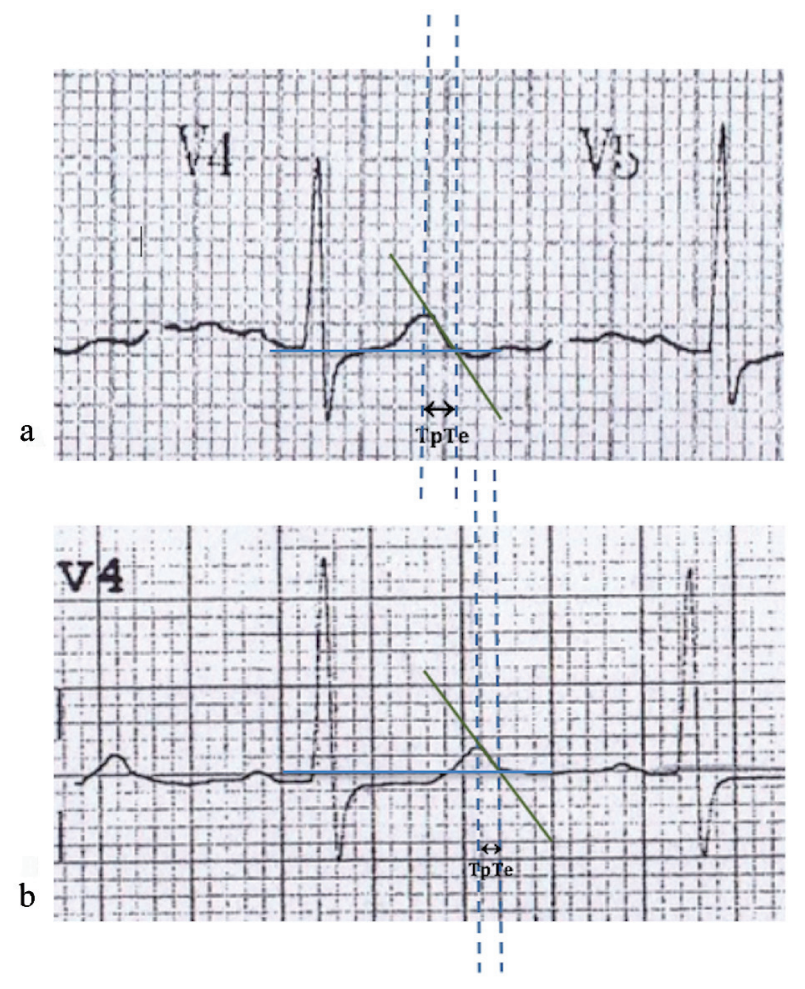

Figure 2. Electrocardiogram example of the effect of beta-blockers on T-peak to T-end (TPTE) interval in a 31-year-old female with PPCM.

the mean of diastolic blood pressure was $76 \pm 6.9 \mathrm{~mm} \mathrm{Hg}$, the mean of heart rate was $114.8 \pm 16.9$ beats $/ \mathrm{min}$. The mean of LVEF was $32.24 \pm 6.3 \%$. The baseline ECGs are shown, and the mean of TPTE interval was $123.7 \pm 28.2 \mathrm{~ms}$. Heart failure therapy administered including beta-blockers $(34 / 34,100 \%)$ that were up-titrated, ACE inhibitors $(34 / 34,100 \%)$, diuretics $(34 / 34,100 \%)$, and mineralocorticoid receptor antagonists $(3 / 34,8 \%)$. Eight patients received bromocriptine $(5 \mathrm{mg}$ per day for 2 weeks, followed by $2.5 \mathrm{mg}$ per day for 4 weeks).

After the mean 6 months of beta-blocker administration, the mean of LVEF was $58.26 \pm 4.4 \%$, and the mean of TPTE was $98.7 \pm 39.5 \mathrm{~ms}$. The Student's $t$-test analysis showed a significant difference between TPTE interval pre- and post-administration of beta-blocker (P value $<0.001$ ) (Table 2 and Figs. 3, 4).

\section{Discussion}

PPCM is a pregnancy-related non-ischemic cardiomyopathy characterized by HF secondary to LV systolic dysfunction. This condition was accompanied with an LVEF $<45 \%$ during the end of pregnancy or in the months following delivery, without any other identifiable explanation for HF [1]. The incidence of PPCM is 1 in 3,500 in USA, 1 in 1,400 in Europe, 1 in 1,000 in South Africa, and 1 in 299 in Haiti [14].

The possibility for ventricular function to have a complete recovery in PPCM patients should be contemplated. A multicentre study which reported outcomes of 30 PPCM patients with subsequent pregnancies showed that the sustained LV 
Table 1. Baseline Characteristics of Patients

\begin{tabular}{|ll}
\hline Variable & Mean \pm SD \\
\hline Age (years) & $32 \pm 6.4$ \\
Body mass index $\left(\mathrm{kg} / \mathrm{m}^{2}\right)$ & $24.87 \pm 3.2$ \\
Blood pressure $(\mathrm{mm} \mathrm{Hg})$ & \\
$\quad$ Systolic & $118 \pm 11.4$ \\
$\quad$ Diastolic & $76 \pm 6.9$ \\
\hline ECG parameters & $114.85 \pm 16.9$ \\
$\quad$ Heart rate (bpm) & $64.42 \pm 18.2$ \\
\hline QRS duration $(\mathrm{ms})$ & $471.50 \pm 440.2$ \\
\hline QTc interval $(\mathrm{ms})$ & \\
Heart failure medications, $\mathrm{n}(\%)$ & $34(100)$ \\
\hline Beta-blockers & $34(100)$ \\
ACE inhibitor & $34(100)$ \\
\hline Diuretics & $3(8.8)$ \\
\hline MRA & $32.24 \pm 6.3$ \\
\hline Echocardiographic data & $1.73 \pm 0.7$ \\
\hline LVEF (\%) & $147.68 \pm 42.6$ \\
\hline Mitral E/A ratio & \\
Deceleration time & \\
\hline
\end{tabular}

SD: standard deviation; bpm: beats per minute; QTC: QT corrected; ACE: angiotensin-converting enzyme; MRA: mineralocorticoid receptor antagonist; LVEF: left ventricular ejection fraction.

dysfunction occurred in half of subjects before the subsequent pregnancy. Sustained normal cardiac features were only presented in 56\% among patients, in whom cardiac function had completely recovered before the following pregnancy. Thus, there is still a considerable chance for relapse in completely recovered LV function in PPCM patients [15].

The prevalence data of ventricular arrhythmias in PPCM patient were limited. Previous study that investigated arrhythmia in PPCM patients by performing Holter analysis in 19 subjects reported the occurrence of sinus tachycardias, premature atrial contractions and premature ventricular contractions of $89.4 \%, 21 \%, 36.8 \%$ respectively; four cases of non-sustained ventricular tachycardias (VTs), and none of the subjects had sustained ventricular arrhythmia [16]. Furthermore, severely reduced LVEF years after the diagnosis and ventricular arrhythmias in PPCM patients were reported by some case reports $[17,18]$. Several studies evaluated outcomes of patients with PPCM demonstrated mortality rates of $7.1 \%$ to $15 \%$ [2, $6,19,20]$. Moreover, Goland et al found $38 \%$ of the deaths of PPCM patients in his cohort study were sudden deaths [2].

The dispersion of ventricular repolarization has been demonstrated to be associated with the TPTE interval on 12-lead resting ECG [7, 21, 22]. Originally, the dispersion was demonstrated in transmural orientation. The repolarization process was started at the epicardium, continued to endocardium, and ended at the midmyocardial "M" cells [23, 24]. Subsequent investigators showed that TPTE represents not only transmural dispersion of ventricular repolarization, but also dispersion of ventricular repolarization of entire myocardial wall [25]. Electrical re-entry requires differential repolarization, so the increased repolarization dispersion could increase arrhythmogenesis [26]. This explanation supported the hypothesis that the longer TPTE correlates with the higher risk of ventricular tachyarrhythmia and death. Hence, several studies have been conducted in various populations to evaluate the role of TPTE in predicting ventricular tachyarrhythmia and/or death [27]. Study performed by Morin et al [26] proved that the longer TPTE strongly predicts both ventricular tachyarrhythmia and death. It is also showed that TPTE correlated with the inducibility of VT/ventricular fibrillation (VF), and the longer TPTE correlated with inducibility of VT at electrophysiology study [25, 28]. Furthermore, TPTE interval on surface ECG was longer in SCD cases and was significantly associated with SCD [29].

Reduction of TPTE was showed after 6-month treatment of beta-blocker administration. A study conducted on patients with type 1 long-QT (LQT1) syndrome to evaluate the effect of beta-blocker administration to TPTE interval, showed that beta-blockers could reduce the prolongations of TPTE at elevated heart rates [30]. This finding is consistent with a previous study, which investigated the effect of propranolol to TPTE interval. Propranolol was demonstrated to suppress the increasing rate-corrected TPTE interval in LQT1 patients caused by epinephrine administration [31]. Earlier experimental studies presented that beta-blocker could inhibit the transiently prolonged duration of $\mathrm{M}$ cell action potential induced by sympathetic, hence prevent the increase of transmural dispersion of repolarization $[11,12]$. We considered the reduction of TPTE interval in our study was not caused by any other

Table 2. Comparisons of Variables Between Before and After Beta-Blocker Treatment

\begin{tabular}{llll}
\hline Variable & Before treatment & After treatment & P value \\
\hline Heart rate (bpm) & $114.85 \pm 16.9$ & $70.65 \pm 10.4$ & $<0.001$ \\
LVEF (\%) & $32.24 \pm 6.3$ & $58.26 \pm 4.4$ & $<0.001$ \\
Mitral E/A & $1.73 \pm 0.7$ & $1.36 \pm 0.3$ & 0.011 \\
Deceleration time (ms) & $147.68 \pm 42.6$ & $174.68 \pm 33.9$ & 0.001 \\
QRS duration (ms) & $64.42 \pm 18.2$ & $60 \pm 12.1$ & 0.420 \\
QTc interval (ms) & $471.50 \pm 440.2$ & $440.17 \pm 24.9$ & 0.082 \\
TPTE (ms) & $123.7 \pm 28.2$ & $98.7 \pm 39.5$ & $<0.001$ \\
\hline
\end{tabular}

LVEF: left ventricular ejection fraction; bpm: beats per minute; QTc: QT corrected; TPTE: T-peak to T-end. P value is considered significant if P < 0.05. 

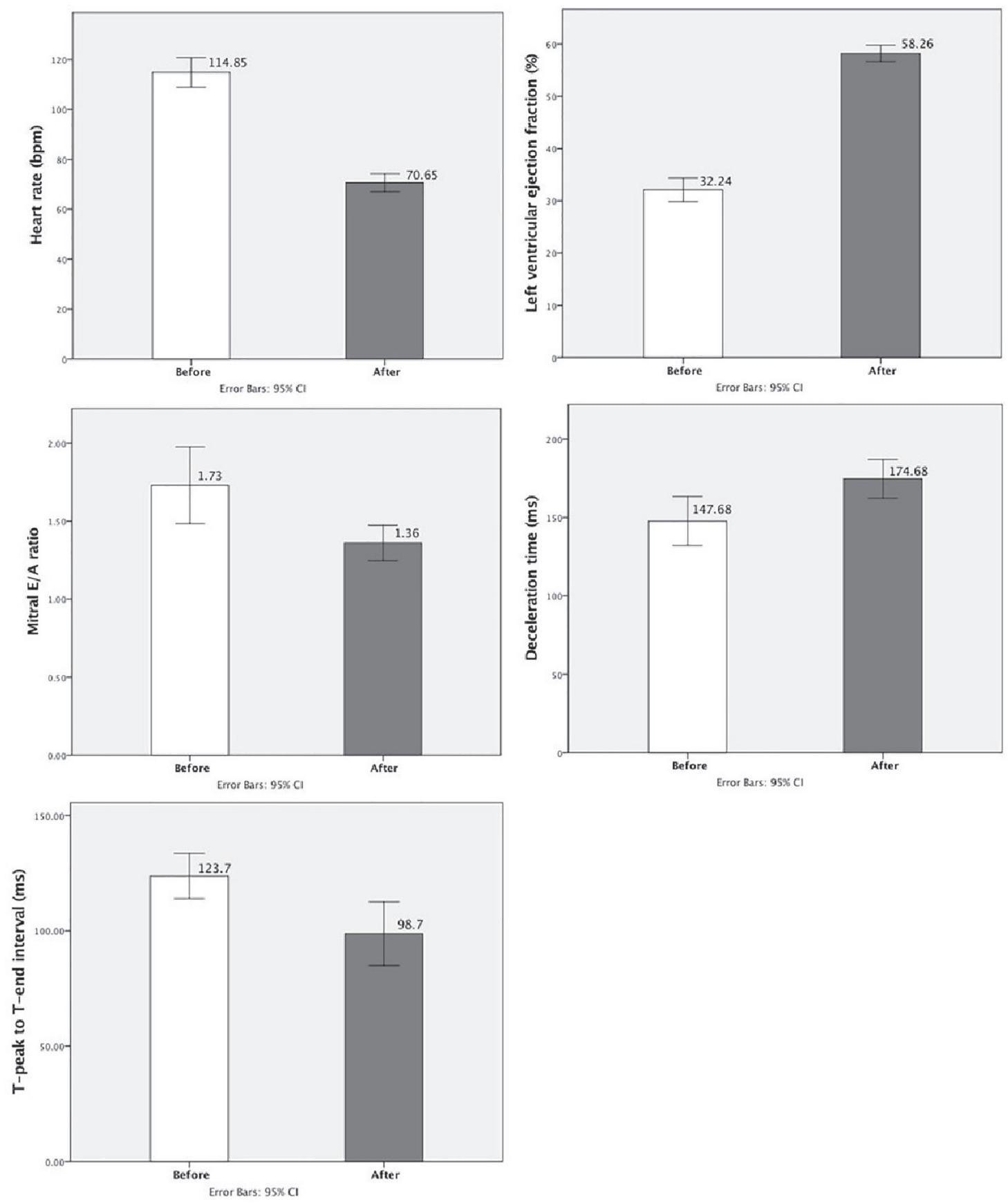

Figure 3. Comparisons of variables between before and after beta-blocker treatment.

drugs such as ACE inhibitors, diuretics, or mineralocorticoid receptor antagonists, as we acknowledged there was no study showed TPTE interval changes related to these drugs.

\section{Limitations}

We focused this study only on the effect of beta-blocker on TPTE interval. Other ECG parameters that could be affected by beta-blocker treatment were not included in this study due to the limitation of data. This study is the first in assessing ventricular repolarization on PPCM patients. We recommend multi-centre and randomized controlled trial (RCT) studies with larger data size for further analysis.

\section{Conclusions}

We observe an improvement of TPTE in PPCM patients after 6 months of beta-blocker administration. Administration of 


\section{TPTE reduction before and after beta blocker administration}

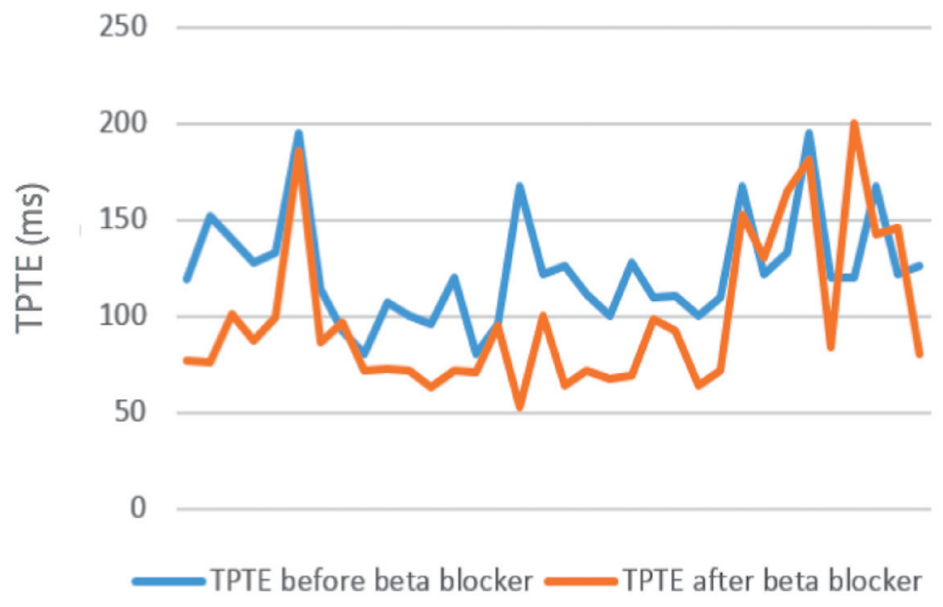

Figure 4. Reduction of T-peak to T-end interval before and after administration of beta-blocker.

beta-blocker in PPCM patients is expected to prevent SCD in PPCM populations.

\section{Acknowledgments}

None to declare.

\section{Financial Disclosure}

None to declare.

\section{Conflict of Interest}

All authors declare no conflict of interest related to this study.

\section{Informed Consent}

Informed consents were obtained.

\section{Author Contributions}

CA made conception and design of study, implemented the study, analysed and interpreted the study results, drafted the manuscript and revised it. MI, GK, HSP, and MF contributed to the design of study, analysis, and interpretation of study data.

\section{Data Availability}

The data that support the findings of this study are available on request from the corresponding author $\mathrm{CA}$.

\section{Abbreviations}

PPCM: peripartum cardiomyopathy; LVEF: left ventricular ejection fraction; SCD: sudden cardiac death; TPTE: T-peak to T-end; ECG: electrocardiogram; ESC: European Society of Cardiology; HF: heart failure; EF: ejection fraction; NYHA: New York Heart Association; FC: functional class; ACE: angiotensin-converting enzyme; SD: standard deviation; VT: ventricular tachycardia; VF: ventricular fibrillation

\section{References}

1. Sliwa K, Hilfiker-Kleiner D, Petrie MC, Mebazaa A, Pieske B, Buchmann E, Regitz-Zagrosek V, et al. Current state of knowledge on aetiology, diagnosis, management, and therapy of peripartum cardiomyopathy: a position statement from the Heart Failure Association of the European Society of Cardiology Working Group on peripartum cardiomyopathy. Eur J Heart Fail. 2010;12(8):767778.

2. Goland S, Modi K, Bitar F, Janmohamed M, Mirocha JM, Czer LS, Illum S, et al. Clinical profile and predictors of complications in peripartum cardiomyopathy. J Card Fail. 2009;15(8):645-650.

3. Sliwa K, Forster O, Tibazarwa K, Libhaber E, Becker A, Yip A, Hilfiker-Kleiner D. Long-term outcome of peripartum cardiomyopathy in a population with high seropositivity for human immunodeficiency virus. Int J Cardiol. 2011;147(2):202-208.

4. Whitehead SJ, Berg CJ, Chang J. Pregnancy-related mortality due to cardiomyopathy: United States, 1991-1997. Obstet Gynecol. 2003;102(6):1326-1331. 
5. Forster O, Hilfiker-Kleiner D, Ansari AA, Sundstrom JB, Libhaber E, Tshani W, Becker A, et al. Reversal of IFNgamma, oxLDL and prolactin serum levels correlate with clinical improvement in patients with peripartum cardiomyopathy. Eur J Heart Fail. 2008;10(9):861-868.

6. Sliwa K, Forster O, Libhaber E, Fett JD, Sundstrom JB, Hilfiker-Kleiner D, Ansari AA. Peripartum cardiomyopathy: inflammatory markers as predictors of outcome in 100 prospectively studied patients. Eur Heart J. 2006;27(4):441-446.

7. Kors JA, Ritsema van Eck HJ, van Herpen G. The meaning of the Tp-Te interval and its diagnostic value. J Electrocardiol. 2008;41(6):575-580.

8. Duncker D, Haghikia A, Konig T, Hohmann S, Gutleben KJ, Westenfeld R, Oswald $\mathrm{H}$, et al. Risk for ventricular fibrillation in peripartum cardiomyopathy with severely reduced left ventricular function-value of the wearable cardioverter/defibrillator. Eur J Heart Fail. 2014;16(12):1331-1336.

9. Priori SG, Napolitano C, Schwartz PJ, Grillo M, Bloise R, Ronchetti E, Moncalvo C, et al. Association of long QT syndrome loci and cardiac events among patients treated with beta-blockers. JAMA. 2004;292(11):1341-1344.

10. Villain E, Denjoy I, Lupoglazoff JM, Guicheney P, Hainque B, Lucet V, Bonnet D. Low incidence of cardiac events with beta-blocking therapy in children with long QT syndrome. Eur Heart J. 2004;25(16):1405-1411.

11. Shimizu W, Antzelevitch C. Cellular basis for the ECG features of the LQT1 form of the long-QT syndrome: effects of beta-adrenergic agonists and antagonists and sodium channel blockers on transmural dispersion of repolarization and torsade de pointes. Circulation. 1998;98(21):2314-2322.

12. Shimizu W, Antzelevitch C. Differential effects of betaadrenergic agonists and antagonists in LQT1, LQT2 and LQT3 models of the long QT syndrome. J Am Coll Cardiol. 2000;35(3):778-786.

13. Moss AJ, Zareba W, Hall WJ, Schwartz PJ, Crampton RS, Benhorin J, Vincent GM, et al. Effectiveness and limitations of beta-blocker therapy in congenital long-QT syndrome. Circulation. 2000;101(6):616-623.

14. Sliwa K, Fett J, Elkayam U. Peripartum cardiomyopathy. Lancet. 2006;368(9536):687-693.

15. Hilfiker-Kleiner D, Haghikia A, Masuko D, Nonhoff J, Held D, Libhaber E, Petrie MC, et al. Outcome of subsequent pregnancies in patients with a history of peripartum cardiomyopathy. Eur J Heart Fail. 2017;19(12):17231728.

16. Diao M, Diop IB, Kane A, Camara S, Kane A, Sarr M, $\mathrm{Ba} \mathrm{SA}$, et al. [Electrocardiographic recording of long duration (Holter) of 24 hours during idiopathic cardiomyopathy of the peripartum]. Arch Mal Coeur Vaiss. 2004;97(1):25-30.

17. Tokuda M, Tedrow UB, Kojodjojo P, Inada K, Koplan BA, Michaud GF, John RM, et al. Catheter ablation of ventricular tachycardia in nonischemic heart disease. Circ Arrhythm Electrophysiol. 2012;5(5):992-1000.

18. Yamada T, McElderry HT, Muto M, Okada T, Murakami Y, Doppalapudi H, Epstein AE, et al. Ventricular arrhyth- mias originating from the epicardial ventricular outflow tract complicated with peripartum cardiomyopathy. J Interv Card Electrophysiol. 2009;25(1):53-57.

19. Blauwet LA, Libhaber E, Forster O, Tibazarwa K, Mebazaa A, Hilfiker-Kleiner D, Sliwa K. Predictors of outcome in 176 South African patients with peripartum cardiomyopathy. Heart. 2013;99(5):308-313.

20. Fett JD, Christie LG, Carraway RD, Murphy JG. Fiveyear prospective study of the incidence and prognosis of peripartum cardiomyopathy at a single institution. Mayo Clin Proc. 2005;80(12):1602-1606.

21. Ibanez A, Ferrero JM. The ECG T-wave duration as an index of dispersion of ventricular repolarization: Insights from simulations. Comput Cardiol. 2006; 33:793796.

22. Xia Y, Liang Y, Kongstad O, Holm M, Olsson B, Yuan S. Tpeak-Tend interval as an index of global dispersion of ventricular repolarization: evaluations using monophasic action potential mapping of the epi- and endocardium in swine. J Interv Card Electrophysiol. 2005;14(2):7987.

23. Antzelevitch C, Shimizu W, Yan GX, Sicouri S, Weissenburger J, Nesterenko VV, Burashnikov A, et al. The M cell: its contribution to the ECG and to normal and abnormal electrical function of the heart. J Cardiovasc Electrophysiol. 1999;10(8):1124-1152.

24. Opthof T, Coronel R, Janse MJ. Is there a significant transmural gradient in repolarization time in the intact heart?: Repolarization Gradients in the Intact Heart. Circ Arrhythm Electrophysiol. 2009;2(1):89-96.

25. Lubinski A, Kornacewicz-Jach Z, Wnuk-Wojnar AM, Adamus J, Kempa M, Krolak T, Lewicka-Nowak E, et al. The terminal portion of the T wave: a new electrocardiographic marker of risk of ventricular arrhythmias. Pacing Clin Electrophysiol. 2000;23(11 Pt 2):1957-1959.

26. Morin DP, Saad MN, Shams OF, Owen JS, Xue JQ, AbiSamra FM, Khatib S, et al. Relationships between the Tpeak to T-end interval, ventricular tachyarrhythmia, and death in left ventricular systolic dysfunction. Europace. 2012;14(8):1172-1179.

27. Smetana P, Schmidt A, Zabel M, Hnatkova K, Franz M, Huber K, Malik M. Assessment of repolarization heterogeneity for prediction of mortality in cardiovascular disease: peak to the end of the $\mathrm{T}$ wave interval and nondipolar repolarization components. J Electrocardiol. 2011;44(3):301-308.

28. Watanabe N, Kobayashi Y, Tanno K, Miyoshi F, Asano T, Kawamura M, Mikami Y, et al. Transmural dispersion of repolarization and ventricular tachyarrhythmias. J Electrocardiol. 2004;37(3):191-200.

29. Panikkath R, Reinier K, Uy-Evanado A, Teodorescu C, Hattenhauer J, Mariani R, Gunson K, et al. Prolonged Tpeak-to-tend interval on the resting ECG is associated with increased risk of sudden cardiac death. Circ Arrhythm Electrophysiol. 2011;4(4):441-447.

30. Viitasalo M, Oikarinen L, Swan H, Vaananen H, Jarvenpaa J, Hietanen H, Karjalainen J, et al. Effects of betablocker therapy on ventricular repolarization documented by $24-\mathrm{h}$ electrocardiography in patients with type 1 
long-QT syndrome. J Am Coll Cardiol. 2006;48(4):747753.

31. Shimizu W, Tanabe Y, Aiba T, Inagaki M, Kurita T, Suyama K, Nagaya N, et al. Differential effects of beta-block- ade on dispersion of repolarization in the absence and presence of sympathetic stimulation between the LQT1 and LQT2 forms of congenital long QT syndrome. J Am Coll Cardiol. 2002;39(12):1984-1991. 